\title{
Spatio-temporal variations in glacier surface velocity in the Himalayas
}

\author{
Yu Zhou ${ }^{1,2}$, Jianlong Chen ${ }^{1,2}$, and Xiao Cheng ${ }^{2,3}$ \\ ${ }^{1}$ Guangdong Provincial Key Laboratory of Geodynamics and Geohazards, School of Earth Sciences and Engineering, Sun \\ Yat-Sen University, Guangzhou 510275, China. \\ ${ }^{2}$ Southern Marine Science and Engineering Guangdong Laboratory (Zhuhai), Zhuhai 519082, China. \\ ${ }^{3}$ School of Geospatial Engineering and Science, Sun Yat-Sen University, Guangzhou 510275, China.
}

Correspondence: Yu Zhou (zhouyu36@mail.sysu.edu.cn); Xiao Cheng (chengxiao9@mail.sysu.edu.cn)

\begin{abstract}
Glacier evolution with time provides important information about climate variability. Here we investigate glacier surface velocity in the Himalayas and analyse the patterns of glacier flow. We collect 220 scenes of Landsat-7 panchromatic images between 1999 and 2000, and Sentinel-2 panchromatic images between 2017 and 2018, to calculate surface velocities of 36,722 glaciers during these two periods. We then derive velocity changes between 1999 and 2018, based on which we perform a detailed analysis of motion of each individual glacier, and noted that the changes are spatially heterogeneous. Of all the glaciers, $32 \%$ have speeded up, $24.5 \%$ have slowed down, and the rest $43.5 \%$ remained stable. The amplitude of glacier slowdown, as a result of glacier mass loss, is remarkably larger than that of speedup. At regional scales, we found that glacier surface velocity in winter has uniformly decreased in the western part of the Himalayas between 1999 and 2018, whilst increased in the eastern part; this contrasting difference may be associated with decadal changes in accumulation and/or melting under different climatic regimes. We also found that the overall trend of surface velocity exhibits seasonal variability: summer velocity changes are positively correlated with mass loss, whereas winter velocity changes show a negative correlation. Our study suggests that glacier velocity changes in the Himalayas are more spatially and temporally heterogeneous than previously thought, emphasising complex interactions between glacier dynamics and environmental forcing.
\end{abstract}

\section{Introduction}

Glaciers are sensitive to climate variability, and are a major contributor to global sea level rise (Kaser et al., 2010; Kääb et al., 2012; Bolch et al., 2012; Yao et al., 2012; Kraaijenbrink et al., 2017; Ren et al., 2006; Brun et al., 2017). It is of great importance to understand glacier evolution with time since it provides direct evidence for climate change (Kääb et al., 2012; Lutz et al., 2014; Dehecq et al., 2019). The Himalayas host the largest volume of glaciers outside the polar regions, which also contribute importantly to water resources for the Indus and Ganges basins (Immerzeel et al., 2009; Guo et al., 2015; Bookhagen and Burbank, 2010). Due to the difficult accessibility of high mountain areas, remote sensing has been a powerful tool for studying the Himalayan glaciers. Researchers have used satellite altimetry (e.g. Kääb et al. 2012; Neckel et al. 2014; Kääb et al. 2015) and optical satellite stereo imagery (e.g. Brun et al. 2017; Maurer et al. 2019; Ragettli et al. 2016) to quantify glacier mass balance in the Himalayas. Although estimates derived from different techniques are dissimilar, they show evidently that the 
Himalayan glaciers are experiencing significant thinning and mass loss, thereby affecting ice fluxes and river discharge. The thinning rate is also suggested to have accelerated in the past 40 years, which is possibly driven by atmospheric warming and associated energy fluxes (Maurer et al., 2019). Recently, Dehecq et al. (2019) investigated the response of glacier flow to mass changes at regional scales. They estimated time-series glacier velocities from 2000 to 2016 using Landsat-7 optical satellite images (Dehecq et al., 2015), and found that the variability in velocity changes within a large region can be explained solely by changes in ice thickness, i.e. ice mass balance (Dehecq et al., 2019). Their study provides a novel way for estimating ice mass balance in the Himalayas as glacier velocity changes can be easily measured with satellite images.

Glacier surface velocity in summer has been heavily exploited, e.g. Dehecq et al. (2015) and Dehecq et al. (2019). Velocity estimates in Dehecq et al. (2019) show that glaciers in the Himalayas have experienced significant slowdown in the past two decades. However, seasonal variability of regional glacier motion remains unclear. The aim of this study is to explore the long-term winter velocity and its changes. We first derive glacier velocities for two periods, 1999-2000 and 2017-2018, using Landsat-7 and Sentinel-2 image pairs respectively. We chose Sentinel-2 over Landsat-7 for mapping present glacier motion because it has been tested to have a better geometric and radiometric quality (Kääb et al., 2016). The uncertainties in the glacier velocities are estimated using the overlapping areas of adjacent image pairs. By differencing the Landsat-7 and Sentinel-2 derived velocities, we map velocity changes over nearly two decades, and combining the data with glacier mass balance, we show the complex patterns of glacier flow in the Himalayas.

\section{Study area and data}

The Himalaya front (Figure 1) stretches over 3,000 km from the west to the east, containing more than 36,000 glaciers of different sizes (Randolph Glacier Inventory, RGI 6.0). The topography increases rapidly across the front, from $200 \mathrm{~m}$ in the south to over 5,000 $\mathrm{m}$ in the north, entering the Tibetan Plateau. Evolution of glaciers in different parts of the Himalayas is affected by different climatic regimes. In the western part, snow accumulation is controlled by westerly atmospheric circulations, so Hindu Kush, Spiti Lahaul and Karakoram receive most accumulation during winter. In the eastern part, the Indian summer monsoon dominates the accumulation in West Nepal, East Nepal, Bhutan and Nyainqentanglha (Azam et al., 2016; Sun et al., 2017; Bookhagen and Burbank, 2010; Kääb et al., 2012; Fujita, 2008). The extreme topography creates additional complexity; precipitation at high-altitude regions has been suggested to be 2-10 times higher than that at low-altitude regions (Immerzeel et al., 2015). As a result, glaciers in the Himalayan front exhibit contrasting variabilities in evolution and mass balance (Kääb et al., 2012; Dehecq et al., 2019; Brun et al., 2017).

In this study, we focus primarily on surface velocity changes of the Himalayan glaciers at decadal scales. Satellite optical images were used to generate glacier velocity maps at different times. We collected 40 pairs of Landsat-7 Level-1T data between 1999 and 2000 to calculate glacier velocity during this period. Each panchromatic Landsat-7 Level-1T image covers an area of $185 \mathrm{~km} \times 170 \mathrm{~km}$, with a spatial resolution of $15 \mathrm{~m}$. 70 panchromatic Sentinel-2A/B Level-1C image pairs were obtained to calculate glacier velocity between 2017 and 2018. Each Sentinel-2 Level-1C image has a footprint of $100 \mathrm{~km} \times 100$ $\mathrm{km}$ and a spatial resolution of $10 \mathrm{~m}$. Dehecq et al. (2019) analysed velocity changes in summer. We are interested to explore 
whether glacier velocities exhibit seasonal variations, so all the 110 pairs of Landsat-7 and Sentinel-2 images used in this study were acquired during winter, centred around December. We also collected glacier geometry data including length, area, slope and thickness from RGI 6.0 and Farinotti et al. (2019), along with satellite-derived glacier elevation changes from Brun et al. (2017), for a comprehensive analysis of glacier velocity changes and the possible driving factors.

\section{Methods and results}

We estimated glacier velocities by applying cross-correlation using the COSI-Corr software package (freely available from www.tectonics.caltech.edu/slip_history/spot_coseis/index.html). Optical correlation is implemented in the frequency domain with an accuracy $\sim 1 / 10$ of the input pixel size (Leprince et al., 2007; Ayoub et al., 2009). We used a correlation window of 64 pixels $\times 64$ pixels as a first step, followed by 32 pixels $\times 32$ pixels for a second run, with a step of 16 pixels $\times 16$ pixels $(160 \mathrm{~m})$ for Sentinel-2A/B data and 10 pixels $\times 10$ pixels $(150 \mathrm{~m})$ for Landsat-7 data. The resulting east-west and northsouth components of the displacement were filtered using the non-local means algorithm (Ayoub et al., 2009). We then used RGI 6.0 to mask out the non-glacial areas and generated two annual velocity fields for 1999-2000 and 2017-2018 for all the 36,722 glaciers within the Himalayas, as shown in Figure 2. The velocity uncertainty was estimated from the overlapping areas between adjacent pairs. The uncertainties are $-3.4 \pm 11.6 \mathrm{~m} \mathrm{yr}^{-1}$ and $0.4 \pm 4.6 \mathrm{~m} \mathrm{yr}^{-1}$ for Landsat-7 and Sentinel-2 derived velocities respectively (Figure 3). Since all the image pairs are centred around December with little interannual fluctuations, the uncertainty depends largely on radiometric quality, indicating that Sentinel-2 imagery has a better radiometric quality than Landsat-7 imagery (Kääb et al., 2016), hence yielding more consistent results.

To calculate velocity changes, we downsampled the Landsat-7 derived velocity map from $150 \mathrm{~m}$ to $160 \mathrm{~m}$ to match the Sentinel-2 derived velocity map, and then differenced the two velocities (Figure 4). Unlike Dehecq et al. (2019) who based their analysis of glacier velocity changes mainly on regions, we conducted our analysis based on individual glacier. For each glacier, we computed its velocity and the associated change by averaging all the pixel values that cover the glacier. A total of 36,722 glaciers were included in our study. As shown in Table 1, 43.5\% of the glaciers remain stable during 1999-2018 (the difference between Landsat-7 and Sentinel-2 velocities is no more than $3 \mathrm{~m} \mathrm{yr}^{-1}$ ), 32.0\% speeded up (velocity changes

$80>3 \mathrm{~m} \mathrm{yr}^{-1}$ ), and the rest $24.5 \%$ slowed down (velocity changes $<-3 \mathrm{~m} \mathrm{yr}^{-1}$ ). Although speedup glaciers outnumber slowdown glaciers, the average amplitude of glacier speedup $\left(6.3 \mathrm{~m} \mathrm{yr}^{-1}\right)$ is much smaller than slowdown $\left(-12.3 \mathrm{~m} \mathrm{yr}^{-1}\right)$. At regional scale, more glaciers in the east of the Himalayas, i.e. West Nepal (33.4\%), East Nepal (56.2\%), Bhutan (34.1\%), and Nyainqentanglha (41.3\%), have experienced speedup than the west in Hindu Kush (22.6\%), Spiti Lahaul (19.6\%) and Karakoram (17.3\%). Karakoram has seen the largest proportion of glacier slowdown (31.5\%), followed by West Nepal (29.1\%), Hindu Kush (28.3\%), Bhutan (22.1\%), Nyainqentanglha (21.9\%), East Nepal (19.6\%) and Spiti Lahaul (18.7\%). The greatest speedup (about $130 \mathrm{~m} \mathrm{yr}^{-1}$ in RGI60-14.04875) and slowdown (about $-250 \mathrm{~m} \mathrm{yr}^{-1}$ in RGI60-14.0300) also occurred in Karakoram. 


\section{Discussion}

\subsection{Relationship between glacier surface velocity and geometry}

We analyse glacier surface velocity in combination with glacier geometry data including area, length, slope and thickness. We use Sentinel-2 derived velocities in the analysis given the smaller measurement uncertainties. Results (Figure 5) show that small glaciers (area $<20 \mathrm{~km}^{2}$ ), regardless of non-surge and surge types, exhibit complex flow velocities, which are poorly correlated with area ( $R=0.13$ for non-surge type and $R=0.22$ for surge type), length ( $R=0.12$ and $R=0.21)$, slope $(R=-0.08$ and $R=0.02)$ and thickness $\left(R=-0.01\right.$ and $R=0.09$ ). Flow velocities of large (area $\geq 20 \mathrm{~km}^{2}$ ), non-surge type glaciers show a positive correlation with both area $(R=0.69)$ and length $(R=0.78)$, i.e. the size of glaciers, suggesting faster motion with increasing sizes. Surge type glaciers do not show an evident correlation with any of the factors. We also noted that glacier velocities appear to be independent of, or at least not linearly correlated with both slope and thickness. Similarly, we analysed the relationship between glacier velocity changes, and glacier size and thickness. As shown in Figure 5, velocity changes of both non-surge and surge type glaciers are completely independent of glacier geometry, indicated by the very low correlation $(R \approx 0)$.

\subsection{Regional patterns of surface velocity changes}

Dehecq et al. (2019) calculated time-series velocity anomalies for 11 subregions in the Himalayas. Here, we follow their line of analysis and focus on the 7 subregions that stretch along the range front. In order to compare our estimates to theirs, we averaged the velocity differences of all glaciers in each subregion, and calculated the rate of change (velocity differences divided by 1.8 decades). Velocity changes (Table 1) show that on average, glaciers in Hindu Kush ( $-1.0 \mathrm{~m} \mathrm{yr}^{-1}$ decade $^{-1}$ for 4,206 glaciers), Karakoram ( $-1.6 \mathrm{~m} \mathrm{yr}^{-1} \mathrm{decade}^{-1}$ for 12,822 glaciers), Spiti Lahaul ( $-0.4 \mathrm{~m} \mathrm{yr}^{-1}$ decade $^{-1}$ for 7,796 glaciers), and West Nepal ( $-0.5 \mathrm{~m} \mathrm{yr}^{-1}$ decade $^{-1}$ for 3,906 glaciers) have slowed down from 1999 to 2018, whereas a slight acceleration occurs in the east: East Nepal ( $0.7 \mathrm{~m} \mathrm{yr}^{-1}$ decade $^{-1}$ for 3,563 glaciers), Bhutan ( $0.2 \mathrm{~m} \mathrm{yr}^{-1}$ decade $^{-1}$ for 1,547 glaciers), and Nyainqentanglha ( $0.2 \mathrm{~m} \mathrm{yr}^{-1}$ decade $^{-1}$ for 2,882 glaciers). Our results differ from Dehecq et al. (2019)'s, who found that all subregions have experienced a slowdown between 2000 and 2017, with a changing rate varying from $-6.4 \mathrm{~m} \mathrm{yr}^{-1} \mathrm{decade}^{-1}$ in Nyainqentanglha to $-1.4 \mathrm{~m} \mathrm{yr}^{-1}$ decade $^{-1}$ in Hindu Kush, except for Karakoram that experienced a small speedup $(0.8 \mathrm{~m}$ $\mathrm{yr}^{-1}$ decade $^{-1}$ ). The inconsistency is likely to be resulted from seasonal changes in glacier flow. The images used in our study were collected in December, so our estimates are velocities during winter, whilst Dehecq et al. (2019)'s velocity estimates are centred around June. Past studies (e.g. Hooke et al. (1989); Lemos et al. (2018); Kraaijenbrink et al. (2016)) have shown that during summer when melting occurs, glaciers flow much faster with stronger temporal and spatial variations. Velocity changes during winter $\left(0 \sim 1 \mathrm{~m} \mathrm{yr}^{-1}\right.$ decade $\left.^{-1}\right)$ are considerably smaller than the changes during summer $\left(1 \sim 6 \mathrm{~m} \mathrm{yr}^{-1} \mathrm{decade}^{-1}\right)$ (see Figure 4 and Table 1), possibly due to strong spatio-temporal variations in melting in the Himalayas. From the winter velocity changes, we also observed a contrasting difference between the western (slowdown) and eastern (speedup) parts of the Himalayan front, indicating heterogeneous changes in accumulation and/or melting under different climatic regimes. 


\subsection{Linking surface velocity changes with glacier mass balance}

To further investigate the driving factors of glacier velocity changes, we use the empirical power law relation between glacier surface velocity $V$ and driving stress $\tau$ (Glen, 1952, 1955; Weertman, 1957; Goldsby and Kohlstedt, 2001):

$V=A \tau^{m}$

where $A$ and $m$ are positive constants, related to ice rheology, bed topography and flow mechanisms (ice deformation and basal sliding) (Glen, 1952, 1955). $m$ has been estimated to vary from 1 (flow over soft sediments, MacAyeal 1989) to 4 (high subglacial pressure, Dehecq et al. 2019) under different circumstances.

Taking the derivative of $V$ with respect to $\tau$, we have:

$d V=A m \tau^{(m-1)} d \tau$

Combining Equations (1) and (2), we have:

$130 \frac{d V}{V}=m \frac{d \tau}{\tau}$

Assuming that changes in the driving stress $(d \tau)$ are induced by mass balance $(d M)$ and ignoring other factors, as proposed by Dehecq et al. (2019), i.e. $d \tau=C_{1} d M+C_{2}$, we have:

$\frac{d V}{V}=\frac{m}{\tau} C_{1} d M+\frac{m}{\tau} C_{2}$

where $C_{1}$ and $C_{2}$ are assumed constant, relating the driving stress and mass balance. Dehecq et al. (2019) analysed velocity changes and mass balance data, and found that at regional scales, summer velocity changes are positively correlated with mass balance: $\frac{d V}{V} \sim 1.25 d M$ (see Figure 6).

To test whether velocity changes exhibit any seasonal variability, we applied Equation (4) to analyse the winter velocity estimates. We calculated the average values of velocity $V$ and its change $d V$ for each of the glaciers, based on which we determined the overall $d V$ and $V$ for each subregion. Measurements of glacier mass balance $(d M)$ were taken from Brun et al. (2017). Although Brun et al. (2017)'s estimates of glacier mass balance did not take seasonal variability into account, earlier study by Kääb et al. (2012) has shown that the long-term trend of $d M$ is consistent between seasons (the amplitude differs slightly). Therefore, using the average long-term trend of $d M$ should not affect the linear relationship between $d V$ and $d M$. As shown in Figure 6, glacier velocity changes $\frac{d V}{V}$ are negatively correlated with mass balance $\left(\frac{d V}{V} \sim-0.96 d M\right)$, suggesting that ice mass loss promotes glacier motion in winter. This is in contrasting difference with summer velocity changes in the study by Dehecq et al. (2019), which states that mass loss drives glacier slowdown. Such seasonal variability indicates different mechanisms of glacier mass loss in the Himalayas. In summer, mass loss is dominated by decrease in precipitation, which will reduce gravitational driving stress, resulting in the long-term glacier slowdown (Dehecq et al., 2019); in winter, mass loss is likely to be controlled by increased melting, which will reduce basal frictional stress and hence promote glacier motion. 
https://doi.org/10.5194/esurf-2021-21

Preprint. Discussion started: 19 March 2021

(c) Author(s) 2021. CC BY 4.0 License.

(c) (i)

\section{Conclusions}

In this study, we used Landsat-7 and Sentinel-2 optical imagery to investigate glacier surface velocity and the associated changes in the Himalayas. We analysed flow patterns of individual glacier along the range front and found that glacier velocity changes exhibit an evident heterogeneity at different spatial scales. Of all the 36,722 glaciers, $32 \%$ have experienced speedup, $24.5 \%$ have slowed down, and the rest $43.5 \%$ remained stable. At regional scales, the amplitude of velocity changes is significantly larger in summer (Dehecq et al., 2019) than that in winter (this study). The decreasing velocities in winter between 1999 and 2018 in the western part of the Himalayas, in contrast to the increasing velocities in the eastern part, may be caused by changes in accumulation and/or melting under different climatic regimes. We also observed that glacier velocity changes in winter are controlled by mass balance, as suggested by Dehecq et al. (2019), but unlike summer velocity changes that are positively correlated with mass balance, winter velocity changes show a negative correlation. Our study suggests that glacier velocity changes in the Himalayas are more spatially and temporally heterogeneous than previously thought, emphasising complex interactions between glacier dynamics and environmental forcing.

Author contributions. Yu Zhou and Jianlong Chen performed data processing. Yu Zhou interpreted the results and wrote the original draft. Xiao Cheng reviewed the paper.

Competing interests. The authors declare that they have no known competing financial interests or personal relationships that could have appeared to influence the work reported in this paper.

Acknowledgements. This work was supported by the Second Tibetan Plateau Scientific Expedition and Research Program (STEP) (2019QZKK0901), National Natural Science Foundation of China (41874020), Guangdong Province Introduced Innovative R\&D Team of Geological Processes and Natural Disasters around the South China Sea (2016ZT06N331) and Deep Earth Exploration and Resource Environment (2017ZT07Z066). Landsat-7 images were downloaded from https://earthexplorer.usgs.gov/; Sentinel-2 images were downloaded from https://scihub.esa.int/. The RANDOLPH GLACIER INVENTORY (RGI 6.0) is freely available from https://www.gtn-g.ch/data_catalogue_rgi/. 
https://doi.org/10.5194/esurf-2021-21

Preprint. Discussion started: 19 March 2021

(c) Author(s) 2021. CC BY 4.0 License.

\section{References}

Ayoub, F., Leprince, S., and Keene, L.: Users Guide to COSI-CORR Co-registration of Optically Sensed Images and Correlation, California Institute of Technology: Pasadena, CA, USA, p. 38, 2009.

Azam, M. F., Ramanathan, A., Wagnon, P., Vincent, C., Linda, A., Berthier, E., Sharma, P., Mandal, A., Angchuk, T., Singh, V., et al.: Meteorological conditions, seasonal and annual mass balances of Chhota Shigri Glacier, western Himalaya, India, Annals of Glaciology, 57, 328-338, 2016.

Bolch, T., Kulkarni, A., Kääb, A., Huggel, C., Paul, F., Cogley, J. G., Frey, H., Kargel, J. S., Fujita, K., Scheel, M., et al.: The state and fate of Himalayan glaciers, Science, 336, 310-314, 2012.

Bookhagen, B. and Burbank, D. W.: Toward a complete Himalayan hydrological budget: Spatiotemporal distribution of snowmelt and rainfall and their impact on river discharge, Journal of Geophysical Research: Earth Surface, 115, 2010.

Brun, F., Berthier, E., Wagnon, P., Kääb, A., and Treichler, D.: A spatially resolved estimate of High Mountain Asia glacier mass balances from 2000 to 2016, Nature Geoscience, 10, 668-673, 2017.

Dehecq, A., Gourmelen, N., and Trouvé, E.: Deriving large-scale glacier velocities from a complete satellite archive: Application to the Pamir-Karakoram-Himalaya, Remote Sensing of Environment, 162, 55-66, 2015.

Dehecq, A., Gourmelen, N., Gardner, A. S., Brun, F., Goldberg, D., Nienow, P. W., Berthier, E., Vincent, C., Wagnon, P., and Trouvé, E.:

Twenty-first century glacier slowdown driven by mass loss in High Mountain Asia, Nature Geoscience, 12, 22-27, 2019.

Farinotti, D., Huss, M., Fürst, J. J., Landmann, J., Machguth, H., Maussion, F., and Pandit, A.: A consensus estimate for the ice thickness distribution of all glaciers on Earth, Nature Geoscience, 12, 168-173, 2019.

Farr, T. G., Rosen, P. A., Caro, E., Crippen, R., Duren, R., Hensley, S., Kobrick, M., Paller, M., Rodriguez, E., Roth, L., et al.: The shuttle radar topography mission, Reviews of Geophysics, 45, 2007.

Fujita, K.: Effect of precipitation seasonality on climatic sensitivity of glacier mass balance, Earth and Planetary Science Letters, 276, 14-19, 2008.

Glen, J.: Experiments on the deformation of ice, Journal of Glaciology, 2, 111-114, 1952.

Glen, J. W.: The creep of polycrystalline ice, Proceedings of the Royal Society of London. Series A. Mathematical and Physical Sciences, 228, 519-538, 1955 .

Goldsby, D. and Kohlstedt, D. L.: Superplastic deformation of ice: Experimental observations, Journal of Geophysical Research: Solid Earth, 106, $11017-11030,2001$.

Guo, W., Liu, S., Xu, J., Wu, L., Shangguan, D., Yao, X., Wei, J., Bao, W., Yu, P., Liu, Q., et al.: The second Chinese glacier inventory: data, methods and results, Journal of Glaciology, 61, 357-372, 2015.

Hooke, R. L., Calla, P., Holmlund, P., Nilsson, M., and Stroeven, A.: A 3 year record of seasonal variations in surface velocity, Storglaciären, Sweden, Journal of Glaciology, 35, 235-247, 1989.

Immerzeel, W., Wanders, N., Lutz, A., Shea, J., and Bierkens, M.: Reconciling high-altitude precipitation in the upper Indus basin with glacier mass balances and runoff, Hydrology and Earth System Sciences, 19, 4673-4687, 2015.

Immerzeel, W. W., Droogers, P., De Jong, S., and Bierkens, M.: Large-scale monitoring of snow cover and runoff simulation in Himalayan river basins using remote sensing, Remote Sensing of Environment, 113, 40-49, 2009.

Kääb, A., Berthier, E., Nuth, C., Gardelle, J., and Arnaud, Y.: Contrasting patterns of early twenty-first-century glacier mass change in the Himalayas, Nature, 488, 495-498, 2012. 
https://doi.org/10.5194/esurf-2021-21

Preprint. Discussion started: 19 March 2021

(c) Author(s) 2021. CC BY 4.0 License.

Kääb, A., Treichler, D., Nuth, C., and Berthier, E.: Brief Communication: Contending estimates of 2003-2008 glacier mass balance over the Pamir-Karakoram-Himalaya., Cryosphere, 9, 2015.

Kääb, A., Winsvold, S. H., Altena, B., Nuth, C., Nagler, T., and Wuite, J.: Glacier remote sensing using Sentinel-2. part I: Radiometric and geometric performance, and application to ice velocity, Remote Sensing, 8, 598, 2016.

Kaser, G., Großhauser, M., and Marzeion, B.: Contribution potential of glaciers to water availability in different climate regimes, Proceedings of the National Academy of Sciences, 107, 20 223-20 227, 2010.

Kraaijenbrink, P., Meijer, S. W., Shea, J. M., Pellicciotti, F., De Jong, S. M., and Immerzeel, W. W.: Seasonal surface velocities of a Himalayan glacier derived by automated correlation of unmanned aerial vehicle imagery, Annals of Glaciology, 57, 103-113, 2016.

215 Kraaijenbrink, P., Bierkens, M., Lutz, A., and Immerzeel, W.: Impact of a global temperature rise of 1.5 degrees Celsius on Asia's glaciers, Nature, 549, 257-260, 2017.

Lemos, A., Shepherd, A., McMillan, M., and Hogg, A. E.: Seasonal variations in the flow of land-terminating glaciers in Central-West Greenland using Sentinel-1 imagery, Remote Sensing, 10, 1878, 2018.

Leprince, S., Barbot, S., Ayoub, F., and Avouac, J.-P.: Automatic and precise orthorectification, coregistration, and subpixel correlation of satellite images, application to ground deformation measurements, Geoscience and Remote Sensing, IEEE Transactions on, 45, 1529$1558,2007$.

Lutz, A., Immerzeel, W., Shrestha, A., and Bierkens, M.: Consistent increase in High Asia's runoff due to increasing glacier melt and precipitation, Nature Climate Change, 4, 587-592, 2014.

MacAyeal, D. R.: Large-scale ice flow over a viscous basal sediment: Theory and application to ice stream B, Antarctica, Journal of Geophysical Research: Solid Earth, 94, 4071-4087, 1989.

Maurer, J., Schaefer, J., Rupper, S., and Corley, A.: Acceleration of ice loss across the Himalayas over the past 40 years, Science Advances, 5, eaav7266, 2019.

Neckel, N., Kropáček, J., Bolch, T., and Hochschild, V.: Glacier mass changes on the Tibetan Plateau 2003-2009 derived from ICESat laser altimetry measurements, Environmental Research Letters, 9, 014 009, 2014.

Ragettli, S., Bolch, T., and Pellicciotti, F.: Heterogeneous glacier thinning patterns over the last 40 years in Langtang Himal, Nepal, The Cryosphere, 10, 2075-2097, 2016.

Ren, J., Jing, Z., Pu, J., and Qin, X.: Glacier variations and climate change in the central Himalaya over the past few decades, Annals of Glaciology, 43, 218-222, 2006.

Sun, Y., Jiang, L., Liu, L., Sun, Y., and Wang, H.: Spatial-temporal characteristics of glacier velocity in the Central Karakoram revealed with 1999-2003 Landsat-7 ETM+ Pan Images, Remote Sensing, 9, 1064, 2017.

Weertman, J.: On the sliding of glaciers, Journal of Glaciology, 3, 33-38, 1957.

Yao, T., Thompson, L., Yang, W., Yu, W., Gao, Y., Guo, X., Yang, X., Duan, K., Zhao, H., Xu, B., et al.: Different glacier status with atmospheric circulations in Tibetan Plateau and surroundings, Nature Climate Change, 2, 663-667, 2012. 


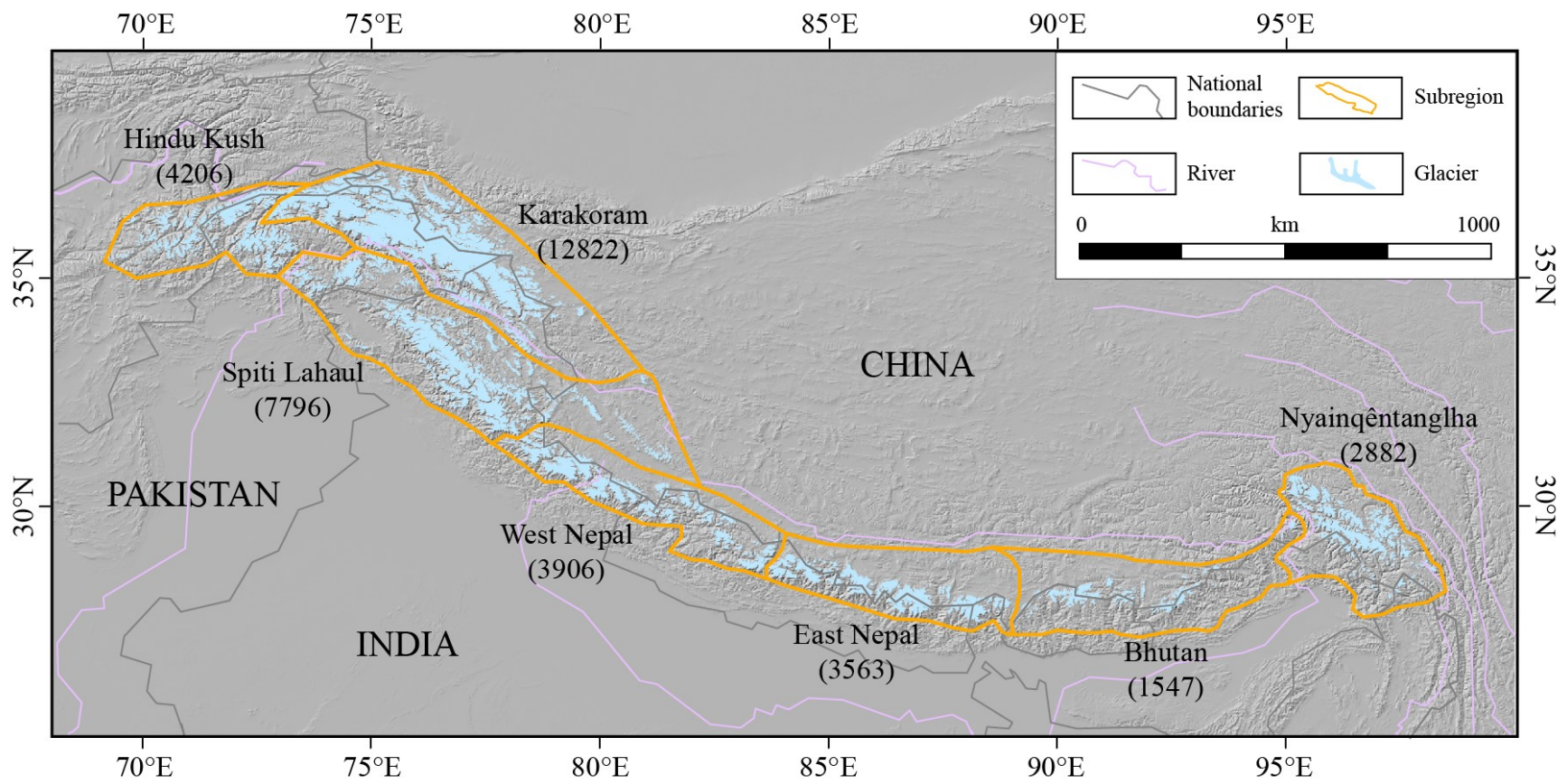

Figure 1. Shaded relief of the Himalaya region generated from the 3 arc second Shuttle Radar Topography Mission (SRTM) DEM (Farr et al., 2007). Glaciers are highlighted in light blue. The total number of glaciers in each subregion is labelled. 


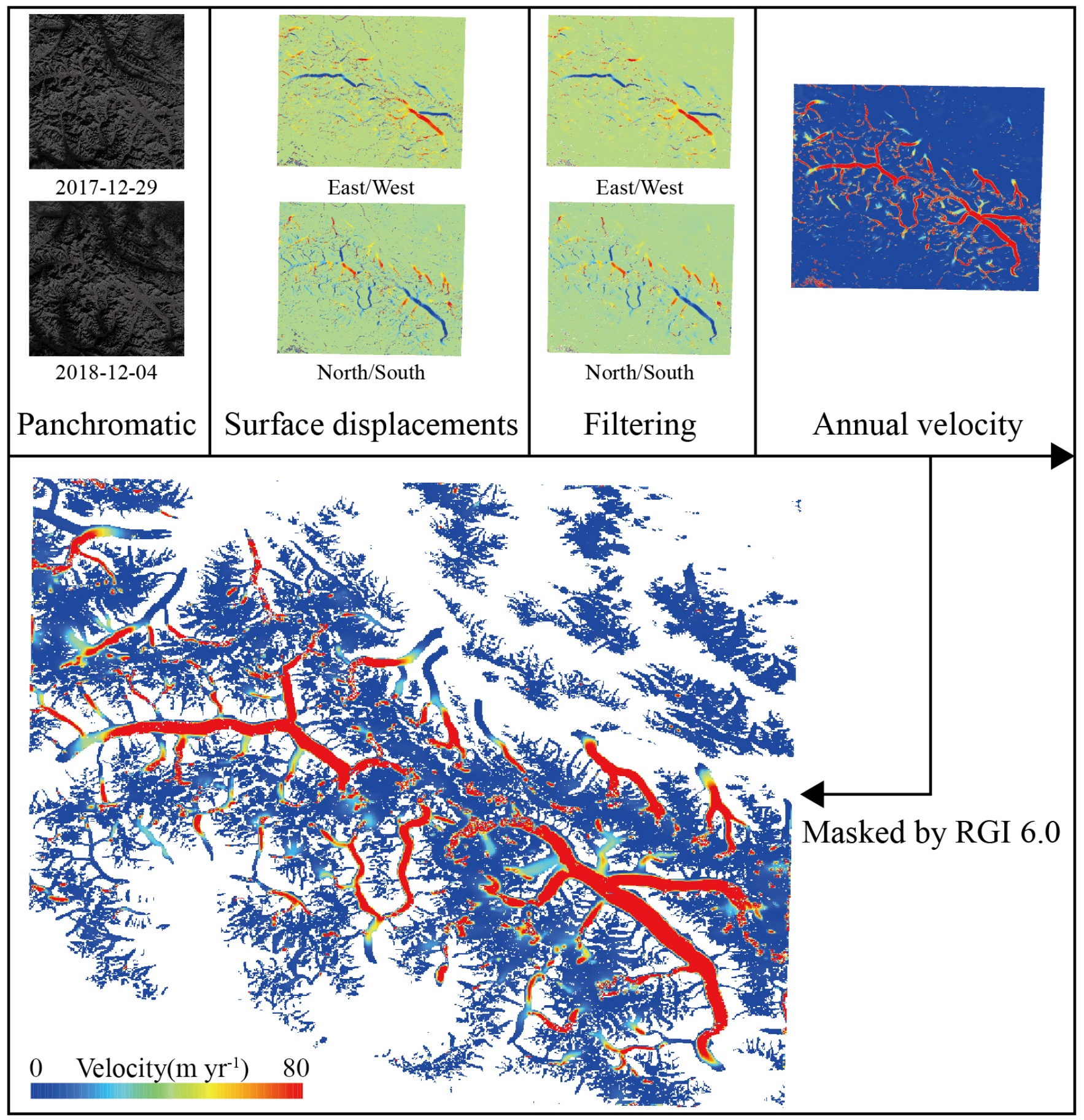

Figure 2. Deriving glacier surface velocity using optical correlation. The Sentinel-2 optical data were provided by the European Space Agency (ESA) via https://scihub.esa.int/. 
https://doi.org/10.5194/esurf-2021-21

Preprint. Discussion started: 19 March 2021

(c) Author(s) 2021. CC BY 4.0 License.

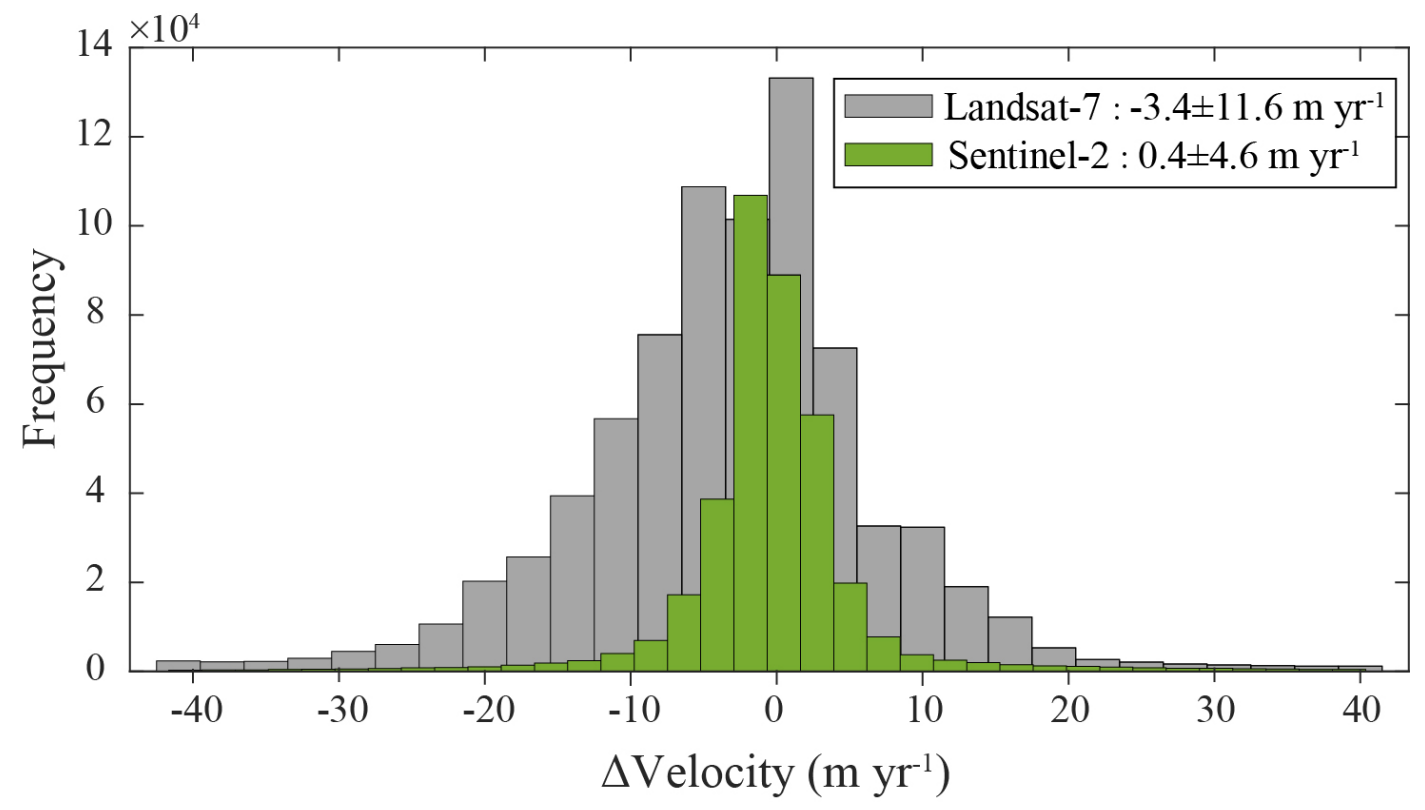

Figure 3. Measurement uncertainties. The uncertainties were calculated from the overlapping areas between adjacent pairs. The Landsat7 and Sentinel-2 derived velocities have a measurement error (mean \pm standard deviation) of $-3.4 \pm 11.6 \mathrm{~m} \mathrm{yr}^{-1}$ and $0.4 \pm 4.6 \mathrm{~m} \mathrm{yr}^{-1}$ respectively. 
https://doi.org/10.5194/esurf-2021-21

Preprint. Discussion started: 19 March 2021

(c) Author(s) 2021. CC BY 4.0 License.
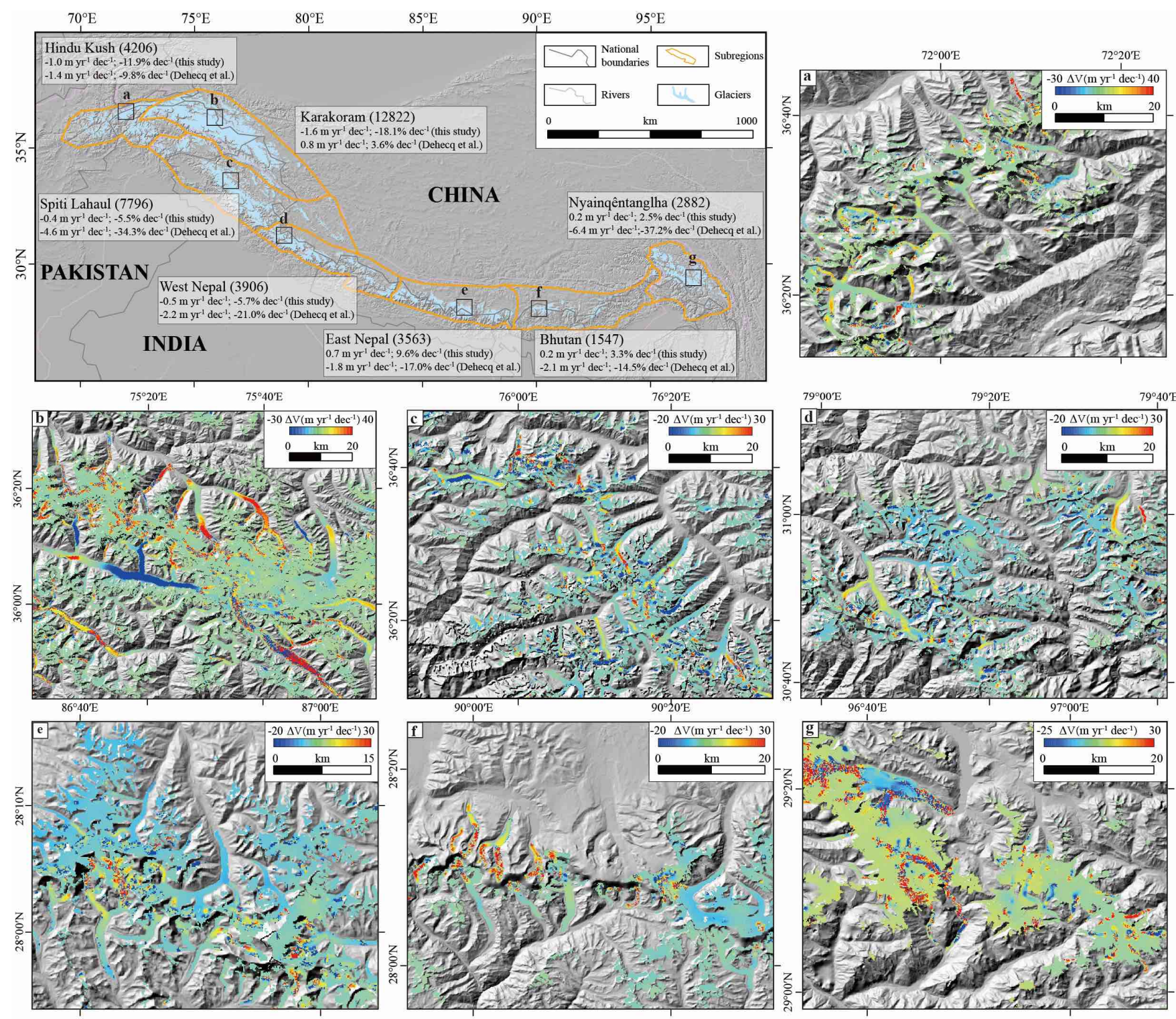

Figure 4. Glacier velocity changes between 1999 and 2018 overlay the shaded SRTM DEM (Farr et al., 2007). We calculated the mean value of velocity changes of each subregion and compared our estimates to Dehecq et al. (2019). Each inset shows an example of velocity changes in a subregion. See Table 1 for details. 

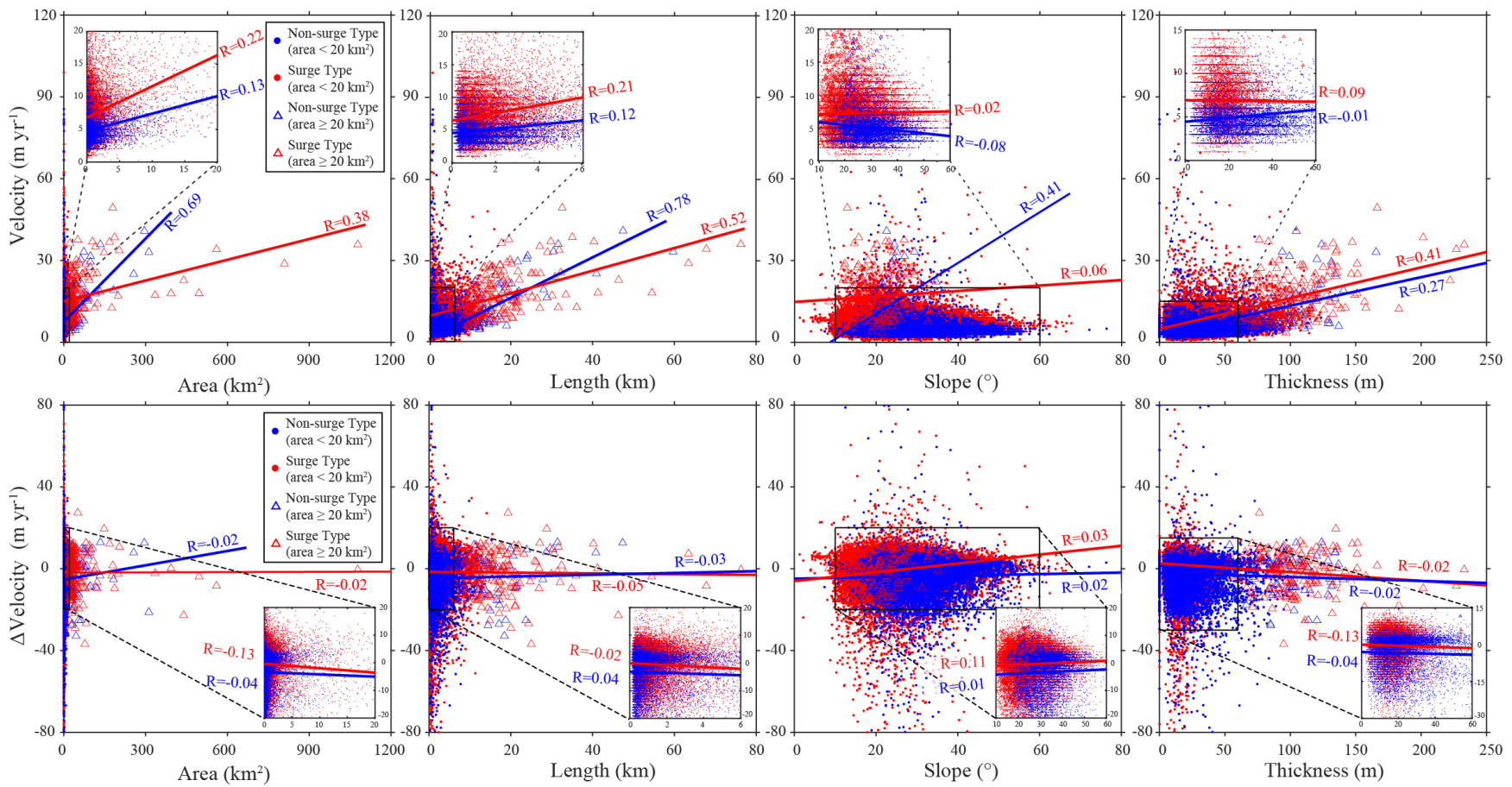

Figure 5. Glacier velocity and velocity changes versus area, length, slope and thickness. Dots and triangles stand for glaciers with an area of smaller $20 \mathrm{~km}^{2}$ and over $20 \mathrm{~km}^{2}$ respectively. Non-surge and surge type glaciers are separated by blue and red. Lines show the linear regression analysis of the corresponding group of data. 


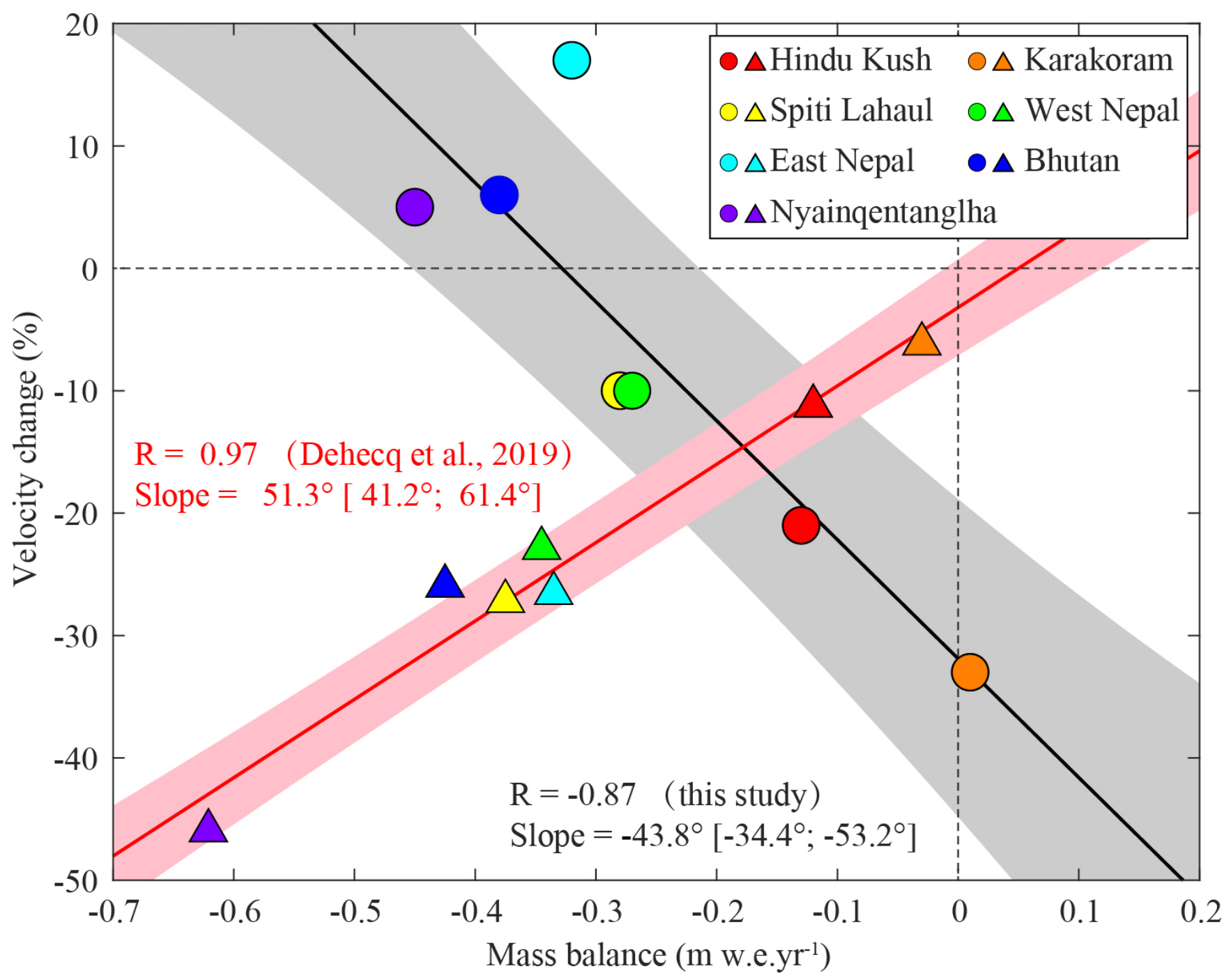

Figure 6. Glacier surface velocity changes versus mass balance. Mass balance data were taken from Brun et al. (2017). Shaded bands indicate $68 \%$ confidence interval. Winter velocity changes (filled circles, this study) are negatively correlated with mass balance, with a correlation of $R=-0.87$. Summer velocity changes (filled triangles, Dehecq et al. (2019)) are positively correlated with mass balance. 
Table 1. Statistics of glacier velocity changes in the Himalayas. Stable glaciers are defined as the amplitude of differences between Landsat-7 and Sentinel-2 velocities, i.e. velocity changes between 1999 and $2018, \leq 3 \mathrm{~m} \mathrm{yr}^{-1}$. Velocity changes $>3 \mathrm{~m} \mathrm{yr}^{-1}$ are regarded as speedup, and $<-3 \mathrm{~m} \mathrm{yr}^{-1}$ slowdown. The overall changes were calculated by averaging all the glaciers within each subregion, in order to be comparable with the results in Dehecq et al. (2019).

\begin{tabular}{|c|c|c|c|c|c|c|c|c|c|c|}
\hline & \multirow{2}{*}{ Number of glaciers } & \multirow{2}{*}{ Speedup } & \multirow{2}{*}{ Slowdown } & \multirow{2}{*}{ Stable } & \multicolumn{2}{|r|}{ Speedup $\left(\mathrm{m} \mathrm{yr}^{-1}\right)$} & \multicolumn{2}{|r|}{ Slowdown $\left(\mathrm{m} \mathrm{yr}^{-1}\right)$} & \multicolumn{2}{|c|}{ Overall $\left(\mathrm{m} \mathrm{yr}^{-1} \mathrm{dec}^{-1}\right)$} \\
\hline & & & & & Average & Maximum & Average & Maximum & this study & Dehecq et al. (2019) \\
\hline Hindu Kush & 4206 & $22.6 \%$ & $28.3 \%$ & $49.1 \%$ & 5.2 & 29.6 (RGI60-14.24088) & -11.5 & -186.0 (RGI60-14.22312) & -1.0 & -1.4 \\
\hline Karakoram & 12822 & $17.3 \%$ & $31.5 \%$ & $51.2 \%$ & 6.6 & 127.7 (RGI60-14.04875) & -13.7 & -256.7 (RGI60-14.03000) & -1.6 & 0.8 \\
\hline Spiti Lahaul & 7796 & $19.6 \%$ & $18.7 \%$ & $61.7 \%$ & 6.4 & 81.5 (RGI60-14.19261) & -12.1 & -179.0 (RGI60-14.17193) & -0.4 & -4.6 \\
\hline West Nepal & 3906 & $33.4 \%$ & $29.1 \%$ & $37.5 \%$ & 5.5 & 27.2 (RGI60-14.12426) & -9.7 & -51.4 (RGI60-15.05231) & -0.5 & -2.2 \\
\hline East Nepal & 3563 & $56.2 \%$ & $19.6 \%$ & $24.2 \%$ & 6.3 & 55.8 (RGI60-15.09859) & -12.3 & $-62.0($ RGI60-15.09861) & 0.7 & -1.8 \\
\hline Bhutan & 1547 & $34.1 \%$ & $22.1 \%$ & $43.8 \%$ & 6.6 & 39.5 (RGI60-15.02102) & -8.5 & -61.3 (RGI60-15.01907) & 0.2 & -2.1 \\
\hline Nyainqentanglha & 2882 & $41.3 \%$ & $21.9 \%$ & $36.8 \%$ & 6.9 & 95.9 (RGI60-15.12714) & -12.4 & -135.6 (RGI60-15.12081) & 0.2 & -6.4 \\
\hline Total & 36722 & $32.0 \%$ & $24.5 \%$ & $43.5 \%$ & 6.3 & 127.7 (Karakoram) & -12.3 & -256.7 (Karakoram) & -0.3 & 1 \\
\hline
\end{tabular}

